\title{
The Effect of Molecular Weight on the Gelation Behavior of Regenerated Silk Solutions
}

\author{
Hee Jung Cho and In Chul Um ${ }^{1, *}$ \\ Department of Advanced Organic Materials Science and Engineering, Kyungpook National University, Daegu 702-701, \\ Republic of Korea \\ ${ }^{1}$ Department of Natural Fiber Science, Kyungpook National University, Daegu 702-701, Republic of Korea
}

(Received 26 August 2011; Accepted 06 September 2011)

\begin{abstract}
The various molecular weight (MW) regenerated silk fibroins were prepared with different dissolution condition and the effect of MW on the gelation behavior of regenerated aqueous silk fibroin (SF) solution was investigated. The result of gelation time measurement indicated that the gelation of SF aqueous solution was accelerated by the increase of $\mathrm{MW}$ and SF concentration. When formic acid was added in SF aqueous solution, the gelation time of SFL and SFC30 aqueous solution showed a significant decreaseat $0.03 \%$ formic acid addition. In case of the lowest MW sample, SFC180, SF molecules became aggregated and precipitated without gelation after 28 days storage time. These findings indicate that MW control of SF can be utilized to control the gelation time of SF aqueous solution.
\end{abstract}

Key words: Regenerated silk fibroin, Molecular weight, Gelation, Formic acid

\section{Introduction}

The regenerated silk fibroin (SF) has attracted researcher's attention due to its unique properties as a biomaterial including good blood compatibility (Sakabe et al., 1989), minimal inflammatory reaction in a body (Meinel et al., 2005), good matrix performance for cell growing (Minoura et al., 1995), etc. With those useful properties, extensive researches regarding application of

\footnotetext{
*To whom the correspondence addressed

Department of Natural Fiber Science, Kyungpook National

University, Daegu 702-701, Republic of Korea.

Tel: +82-53-950-7757; Fax: +82-53-950-6744;

E-mail: icum@knu.ac.kr
}

SF to biotechnological fields have been performed, recently. For those applications, the SF has been fabricated to fiber (Ki et al., 2007; Um et al., 2004), nano web (Ki et al., 2008; Sukigaraet al., 2003), film (Kweonet al., 2001; Mathuret al., 1997), powder (Yoshimizu and Asakura, 1990), and gel forms (Kang et al., 2000; Wang et al., 2008), etc.

The SF aqueous solution becomes a gel when it is stored for a certain period. The gelation of SF aqueous solution takes place because the molecular network of SF molecules is formed. It has been reported that SF molecules rearrange from a random coil conformation to beta sheet conformation during the gelation process (Nagarkaret al., 2010). Recently, SF gel has attracted researcher's attention because the high strength of SF gel, its porosity and its biocompatibility make it a potentially interesting biomaterial (Nagarkaret al., 2010).

Molecular weight (MW) of polymer has an important role in determining the structure and properties of polymer. Though it is also expected that MW of SF strongly influences the gelation behavior of SF aqueous solution, the effect of MW of SF on the gelation was not studied in detail, yet.

Therefore, in this study, various MW SF aqueous solutions were prepared by different dissolution condition and the effect of MW on the gelation behavior of SF aqueous solution was examined.

\section{Materials and Methods}

\section{Preparation}

Bombyxmori cocoons were degummed with sodium oleate $0.3 \%$ (o.w.f.) and sodium carbonate $0.2 \%$ (o.w.f.) solution at a boiling temperaturefor $1 \mathrm{hr}$, and then rinsed thoroughly in distilled water and dried to obtain SF. The 
Table 1. Sample codes of various MW SF samples prepared by different dissolution conditions

\begin{tabular}{cccc}
\hline $\begin{array}{c}\text { Sample } \\
\text { code }\end{array}$ & Solvent & $\begin{array}{c}\text { Dissolution } \\
\text { temperature } \\
\left({ }^{\circ} \mathrm{C}\right)\end{array}$ & $\begin{array}{c}\text { Dissolution } \\
\text { time } \\
(\mathrm{min})\end{array}$ \\
\hline SFL & $\begin{array}{c}9.3 \mathrm{LiBr} \text { aqueous } \\
\text { solution }\end{array}$ & 25 & 360 \\
\hline SFC3 & $\begin{array}{c}\mathrm{CaCl} / \mathrm{H}_{2} \mathrm{O} / \mathrm{EtOH} \\
\text { solution } \\
(1 / 8 / 2 \text { mole ratio })\end{array}$ & 85 & 3 \\
\hline SFC30 & $\begin{array}{c}\mathrm{CaCl} / \mathrm{H}_{2} \mathrm{O} / \mathrm{EtOH} \\
\text { solution } \\
(1 / 8 / 2 \text { mole ratio })\end{array}$ & 85 & 30 \\
\hline SFC180 & $\begin{array}{c}\mathrm{CaCl} / \mathrm{H}_{2} \mathrm{O} / \mathrm{EtOH} \\
\text { solution } \\
(1 / 8 / 2 \text { mole ratio })\end{array}$ \\
\hline
\end{tabular}

SFs were dissolved by 4 different dissolution conditions to prepare 4 different MW regenerated SFs. The sample code of regenerated SF and dissolution conditions were listed in Table 1.

The aqueous SF solutions were obtained through the dialysis of the dissolved SF solutions in a cellulose tube (molecular cut off $=12,000 \sim 14,000$ ) against a circulating pure water for 5 days at room temperature. The concentration of aqueous SF solution was measured with Moisture Balance (XM60, Precisa, Swiss) and 1 2\% (w/v) concentration of aqueous SF solution was obtained. $1 \%$ (w/v) SF aqueous solution were prepared by adding distilled water into the SF solution and $5 \%(\mathrm{w} / \mathrm{v})$ solution were obtained by evaporating water in the SF solution with drying oven at $60^{\circ} \mathrm{C} .0 .01 \sim 30 \%(\mathrm{v} / \mathrm{v})$ regenerated SF formic acid aqueous solutions were prepared by adding formic acid into regenerated SF aqueous solution and by mixing them carefully.

\section{Measurement}

The regenerated SF solutions were stored in $20 \mathrm{ml}$ vial in convection oven at $25^{\circ} \mathrm{C}$. The vial was tilted to check if the gelation took place. The gelation time was determined by the time the SF solution did not flow when the solution was tilted. The several vials for each SF sample were prepared to use them once for the gelation test because the tilted SF solution in vial could not be used in the gelation test again.

\section{Results and Discussion}

In other study, it isfound by fast protein liquid chromatography that the various MW SFs could be prepared by

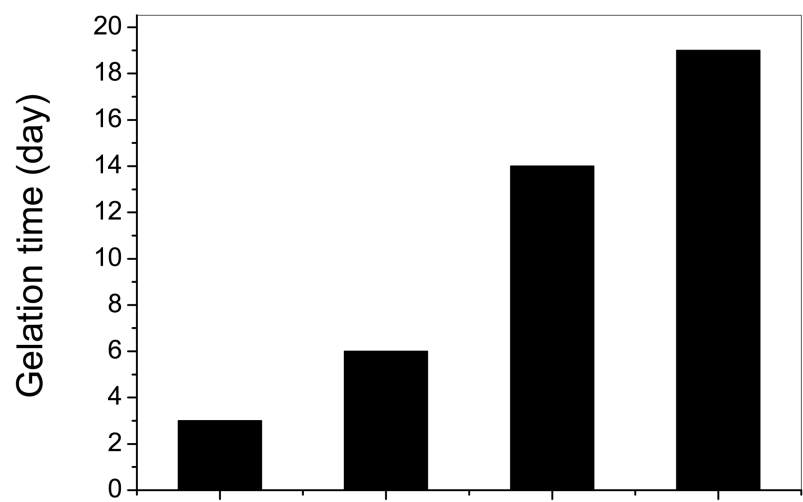

(a)

(b)

(c)

(d)

Dissolution condition

Fig. 1. Gelation time of 1\% regenerated SF aqueous solutions with different dissolution condition; (a) SFL, (b) SFC3, (c) SFC30, and (d) SFC180.

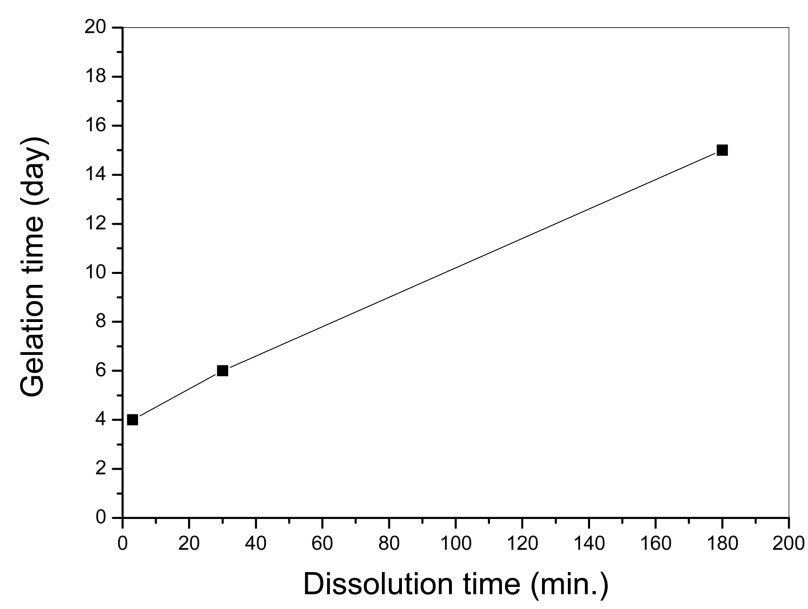

Fig. 2. The effect of dissolution time in $\mathrm{CaCl}_{2} / \mathrm{H}_{2} \mathrm{O} / \mathrm{EtOH}$ solution on the gelation time of $5 \%$ regenerated $\mathrm{SF}$ aqueous solution.

different dissolution condition (Cho et al., 2011). In addition, it was revealed that the MW order of SF samples was as follows; SFL $>$ SFC3 $>$ SFC30 > SFC180.

Fig. 1 exhibited the effect of $\mathrm{MW}$ on the gelation time of $1 \%$ regenerated SF aqueous solution. The SFL aqueous solution produced by dissolution in $9.3 \mathrm{M} \mathrm{LiBr}$ aqueous solution, the highest MW sample, became a gel in 3 days. As the MW of SF decreased, the gelation time decreased. The gelation time of 5\% regenerated SF aqueous solutionswere also measured to examine the effect of SF concentration on the gelation behavior. As shown in Fig. 2, 5\% SFC3, SFC30, and SFC180 solutions exhibited a reduced gelation time compared to $1 \%$ SF solutions.

These results imply the high MW and concentration accelerates the gelation of SF aqueous solution. Kim et al. (2004) reported that gelation occurs because of the for- 


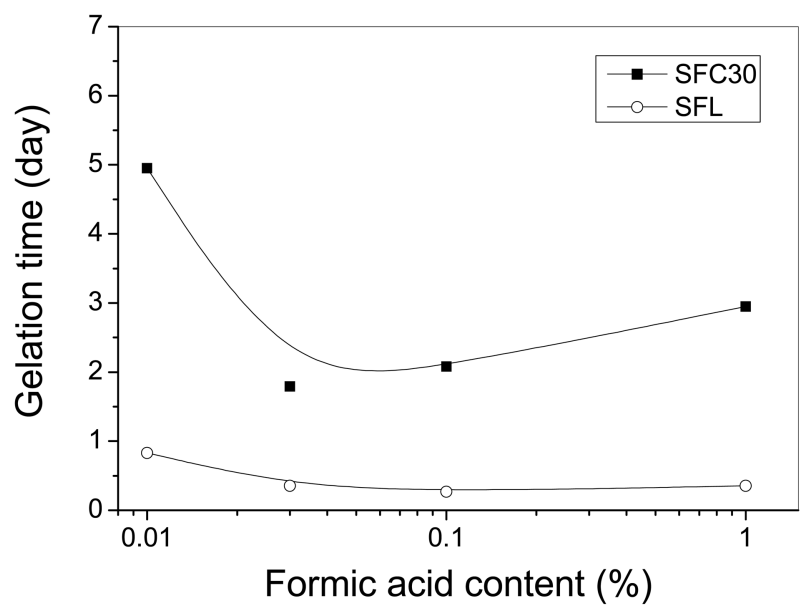

Fig. 3. The effect of formic acid content on the gelation time of $1 \%$ regenerated SF formic acid aqueous solutions with different dissolution condition.

mation of inter- and intramolecular interactions among the protein chains including hydrophobic interactions and hydrogen bonds. Kang et al. (2000) reported that the gelation time of SF aqueous solution decreased, as the SF concentration increased from $1.43 \mathrm{wt} \%$ to $2.98 \mathrm{wt} \%$. Kweon et al. (2001) reported that the gelation of silk sericin aqueous solution accelerated with an increase of silk sericin concentration. Also, the gelation of polymer is a result of network formation of polymer molecules in a solution. Therefore, this result can be easily understood based on those findings. That is, as MW and concentration increased, the network formation between SF molecules becomes easier resulting in a decrease of gelation time.

It is well known that $\mathrm{pH}$ strongly influences the gelation behavior of regenerated SF solution. SF is a protein material and has an isoelectric point at $\mathrm{pH}=3.8 \sim 3.9$ (Heider et al., 1993). Therefore, the gelation of SF solution takes place easily when the $\mathrm{pH}$ approaches the isoelectric point. Various formic acid contents were added in SF aqueous solutions to investigate the effect of formic acid content on gelation behavior of the different MW SF solutions. Fig. 3 presents the gelation time of SF solution added with various formic acid contents.

Regardless of MW, the gelation time decreased significantly at $0.03 \%(\mathrm{v} / \mathrm{v})$ formic acid content. In case of SFC30, gelation time increased slightly after $0.03 \%$ formic acid addition. There was almost no change in the gelation time of SFL solution after $0.03 \%$. It seems that the fastest gelation of SFL and SFC30 at $0.03 \sim 0.1 \%$ formic acid content is due to that their $\mathrm{pH}$ approaches isoelectric point. On the whole, though there is a difference in the gelation time between SFL and SFC30, the trend of gelation time by addition of formic acid is quite similar.
However, different gelation behavior was observed in the smallest MW sample, SFC180 produced by dissolution in $\mathrm{CaCl}_{2}$ mixed solvent for 3 hours. In case of SFL, it showed a gelation at $0.01 \%$ formic acid and no gelation at $30 \%$ formic acid (Data is not shown here). On the other hand, SFL180 did not display a gelation state. In case of $0.01 \%$ formic acid addition, it is observed that there is a precipitation of SF aggregates. For 30\% formic acid, no precipitation nor gelation was observed.

Considering formic acid is a good solvent and stabilizing agent for SF (Um et al., 2003), it can be easily understood that the relatively transparent SF solution state at $30 \%$ formic acid regardless of MW. Aggregation and precipitation of SFC180 solution at $0.01 \%$ formic acid can be explained by molecular size. As mentioned above, the gelation takes place when polymer molecules construct the network structure with neighboring molecules. However, in case of the smallest MW sample, SFC180, the chain size is not long enough to build network with neighboring molecules.

In this study, the various MW SFs were fabricated by different dissolution condition and the effect of MW on the gelation behavior of SF aqueous solution. As a result, it was confirmed that MW influences significantly the gelation behavior of SF aqueous solution. The gelation time could be controlled variably by MW of SF. In particular, it was found that the gelation did not take place, when the MW of SF decreased to a certain level. It was also learned that high MW reduced remarkably the gelation time of SF aqueous solution. These findings can be utilized in application of SF to biomedical fields. It is necessary to study the gel strength of SF gel with various MWs for the application of SF gel. This study will be performed as a subsequent study.

\section{Acknowledgement}

This research was supported by Basic Science Research Program through the National Research Foundation of Korea (NRF) funded by the Ministry of Education, Science and Technology (2009-0067580) and a grant (2008FTH010102001) from BioGreen21 Program, Rural Development Administration, Republic of Korea.

\section{References}

Cho HJ, Ki CS, Oh H, Lee KH, Um IC (2011) Solution properties and Structural Characteristics of Various Molecular Weight Regenerated Silk Fibroins Prepared by Different Dissolution Condition. In preparation. 
Haider ZA, Aria M, Hirabayashi K (1993) Mechanism of the gelation of fibroin solution. Biosci Biotechnol Biochem 57, 1910-1912.

Kang GD, Nahm JH, Park JS, Moon JY, Cho CS, Yeo JH (2000) Effects of poloxamer on the gelation of silk fibroin. Macromol Rapid Commun 21,788-791.

Ki CS, Kim JW, Oh HJ, Lee KH, Park YH (2007) The effect of residual silk sericin on the structure and mechanical property of regenerated silk filament. Int J Biol Macromol 41, 346353.

Ki CS, Park SY, Kim HJ, Jung HM, Woo KM, Lee JW, Park YH (2008) Development of 3-D nanofibrous fibroin scaffold with high porosity by electrospinning: implications for bone regeneration. Biotech Lett 30, 405-410.

Kim J, Park J, Li C, Jin H, Valluzzi R, Kaplan DL (2004) Structure and properties of silk hydrogels. Biomacrmolecules 5, 786-792.

Kweon HY, Ha HC, Um IC, Park YH (2001) Physical properties of silk fibroin/chitosan blend films. J Appl Polym Sci 80, 928-934.

Kweon HY, Yeo JH, Lee KG, Lee YW, Park YH, Nahm J, Cho C (2001) Effects of poloxamer on the gelation of silk sericin. Macromol Rapid Commun 21, 1302-1305.

Mathur AB, Tonelli A, Rathke T, Hudson S (1997) The dissolution and characterization of Bombyxmori silk fibroinin calcium nitrate methanol solution and the regeneration of films. Biopolymers 42, 61-74.

Meinel L, Hofmann S, Karageorgiou V, Kirker-Head C, McCool J, Gronowicz G, Zichner L, Langer R, Vunjak-
Novakovic G, Kaplan DL (2005) The inflammatory responses to silk films in vitro and in vivo. Biomaterials 26, 147-155.

Minoura N, Aiba S, Gotoh Y, Tsukada M, Imai Y (1995) Attachment and growth of cultured fibroblast cells on silk protein matrixes. J Biomed Mater Res 29, 1215-1221.

Nagarkar S, Nicolai T, Chsssenieux C, Lele A (2010) Structure and gelation mechanism of silk hydrogels. Phys Chem Chem Phys 12, 3834-3844.

Sakabe H, Ito H, Miyamoto T, Noishiki, Ha WS (1989) In vivo blood compatibility of regenerated silk fibroin. Sen-i Gakkaishi 45, 487-490.

Sukigara S, Gandhi M, Ayutsede J, Micklus M, Ko F (2003) Regeneration of Bombyxmori silk by electrospinning. part 1: processing parameters and geometric properties. Polymer 44, 5721-5727.

Um IC, Ki CS, Kweon H, Lee GK, Ihm DW, Park YH (2004) Wet spinning of silk polymer: II. Effect of drawing on the structural characteristics and properties of filament. Int $\mathbf{J}$ Biol Macromol 34, 107-119.

Um IC, Kweon HY, Lee KG, Park YH (2003) The role of formic acid in solution stability and crystallization of silk protein polymer. Int J Biol Macromol 33, 203-213.

Wang XQ, Kluge JA, Leisk GG, Kaplan DL (2008) Sonicationinduced gelation of silk fibroin for cell encapsulation. Biomaterials 29, 1054-1064.

Yoshimizu H, Asakura T (1990) Preparation and characterization of silk fibroin powder and its application to enzyme immobilization. J Appl Polym Sci 40, 127-134. 